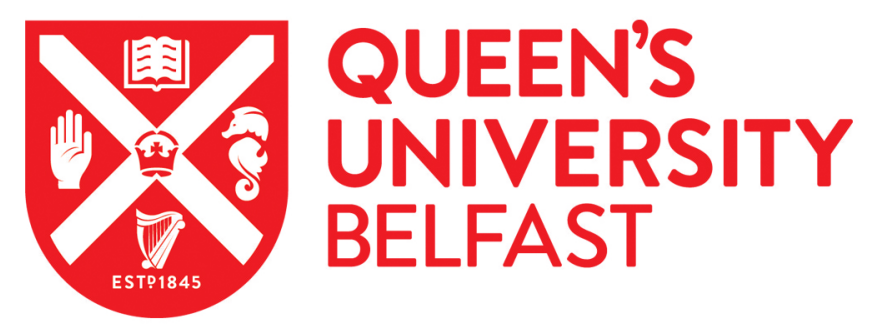

\title{
Supports and barriers to implementation of routine clinical assessment for children with cerebral palsy: A mixed-methods study
}

Kerr, C., Shields, N., Quarmby, L., Roberts, K., Imms, C., \& 'Best Service at the Best Time’ group * (2016).

Supports and barriers to implementation of routine clinical assessment for children with cerebral palsy: A mixedmethods study. Disability and Rehabilitation, 4O(4), 425. https://doi.org/10.1080/09638288.2016.1258736

Published in:

Disability and Rehabilitation

Document Version:

Peer reviewed version

Queen's University Belfast - Research Portal:

Link to publication record in Queen's University Belfast Research Portal

\section{Publisher rights}

(c) 2016 Informa UK Limited

This is an Accepted Manuscript of an article published by Taylor \& Francis in Disability and Rehabilitation on 15 Dec 2016, available online: http://www.tandfonline.com/doi/full/10.1080/09638288.2016.1258736

\section{General rights}

Copyright for the publications made accessible via the Queen's University Belfast Research Portal is retained by the author(s) and / or other copyright owners and it is a condition of accessing these publications that users recognise and abide by the legal requirements associated with these rights.

Take down policy

The Research Portal is Queen's institutional repository that provides access to Queen's research output. Every effort has been made to ensure that content in the Research Portal does not infringe any person's rights, or applicable UK laws. If you discover content in the Research Portal that you believe breaches copyright or violates any law, please contact openaccess@qub.ac.uk. 
Title: Supports and barriers to implementation of routine clinical assessment for children with cerebral palsy: a mixed-methods study

Authors: Claire Kerr ${ }^{1,2}$, Nora Shields ${ }^{3,4}$, Lyndsay Quarmby ${ }^{5,6}$, Karen Roberts ${ }^{7}$, Christine Imms $^{1}$ and the 'Best Service at the Best Time' group*

${ }^{1}$ Centre for Disability and Development Research, Australian Catholic University, Locked Bag 4115, Fitzroy, Victoria, 3065, Australia; ${ }^{2}$ School of Nursing and Midwifery, Queen's University Belfast, Medical Biology Centre, 97 Lisburn Road, Belfast, BT9 7BL, United Kingdom; ${ }^{3}$ La Trobe University, Department of Physiotherapy, School of Allied Health, Bundoora, VIC, 3086, Australia; ${ }^{4}$ Northern Health, Melbourne, Australia; ${ }^{5}$ St Giles, 65 Amy Road, Tasmania, 7248 , Australia; ${ }^{6}$ Centre for Rural Health, University of Tasmania, Locked Bag 1322, Launceston, Tasmania, 7250, Australia; ${ }^{7}$ Alfred Health, Victoria, Australia

*'Best Service at the Best Time' group listed in the Acknowledgements section 


\section{Abstract}

Purpose: To investigate supports and barriers to evidence-based routine clinical assessment of children with cerebral palsy.

Method: This mixed methods study included physiotherapists, occupational therapists and speech pathologists providing services to children with cerebral palsy (3-18 years) within five organisations across Australia. Four organisations initiated standardised routine clinical data collection (Commencing organisations) and one had previously mandated routine assessment (Comparison organisation). Participants completed the Supports and Barriers Questionnaire $(n=227)$ and participated in focus groups ( $n=8$ groups, 37 participants). Quantitative data were summarised descriptively, qualitative data were analysed thematically and comparisons between organisations assessed.

Results: Organisational structures, resources, therapists within organisations, assessment tools, and children and families were, on average, viewed as supportive of routine clinical assessment. There were no differences between the Comparison and Commencing organisations except 'therapists within the organisation' were viewed as more supportive by the Commencing organisations $(p=0.037)$. Five themes were derived from qualitative analyses: motivation to adopt routine clinical practice; acquiring and utilising expertise; ensuring effective ongoing communication; availability and distribution of resources; and therapist perceptions of child and family wishes.

Conclusions: Organisations experience challenges to effective and sustained implementation of routine clinical assessment. Adequate resourcing and positive, clear communication were perceived as critical for success. 
Routine clinical assessment of musculoskeletal outcomes is effective in reducing long term impairment and consequent disability in children with cerebral palsy ${ }^{1,2}$. Cerebral palsy is a life-long condition arising from a non-progressive disorder of the central nervous system that results in a primary motor disorder and associated activity limitations ${ }^{3}$. Disability associated with the condition increases with age: musculoskeletal contractures have been reported by $80 \%$ of adults with cerebral palsy ${ }^{4}$. Contractures can result in pain, difficulties in walking, as well as difficulties in achieving and maintaining comfortable lying and sitting positions, and personal care tasks ${ }^{1}$. Children with cerebral palsy utilise a range of specialist health services including occupational therapy, physiotherapy and speech pathology to help minimise impairment, maximise activity performance and optimise their participation. Routine clinical assessment is a central component of allied health services and is associated with earlier detection of hip displacement and joint contracture, which allows earlier referral for intervention. As a result of these practices, severe orthopaedic deformities in children with cerebral palsy, such as hip dislocation, have been almost eliminated in Sweden ${ }^{1}$. However, in Australia there are no consistent processes to support allied health professionals to implement this evidence-based approach.

Knowledge translation (KT) is "the exchange, synthesis and ethically-sound application of knowledge...to accelerate the capture of the benefits of research for [people] through improved health, more effective services and products, and a strengthened health care service ${ }^{\prime 5}$. Evidence shows specific knowledge translation strategies are required to support changes in clinical practice to ensure uptake of new evidence ${ }^{6}$. There are numerous barriers to implementing evidence-based clinical practices including practitioner knowledge, attitudes and skills; workplace resources and policies; educational barriers related to lack of suitable training opportunities; and/or patientrelated barriers about perceptions of effective health care ${ }^{7-9}$. What is less well known is how supports and barriers work together within particular organisations and the influence of organisational structures and processes on evidence uptake in service provision. 
We proposed to address the problem of how to embed routine, evidence-based, clinical assessment into organisations providing allied health professional services for children with cerebral palsy and their families. Our aim was to investigate the supports, barriers and strategies that might influence the uptake of evidence-based practices, such as routine clinical assessment, within these organisations. Our specific research questions were:

1. To what extent do allied health professionals perceive organisational structure; organisational resources; therapists; outcome measures; and children and families, to be a support or barrier to implementation of routine clinical assessment of children with cerebral palsy?

2. Do the supports and barriers perceived by allied health professionals differ between organisations?

\section{Methods}

\section{Study Design}

A mixed methods study ${ }^{10}$ was completed: quantitative and qualitative data were collected concurrently. A convergent parallel approach was modified slightly in that data were collected concurrently, however analyses were not used to confirm findings from one dataset to the other, but rather a more integrative analysis of both quantitative and qualitative data was undertaken to address the research aim. Using this approach allowed a quantitative summary of findings to be generated for comparative purposes and obtained qualitative data to provide a more detailed view of the perspectives within each organisation.

This study was nested within a larger pragmatic pre-post knowledge translation study ${ }^{11}$. The larger study aimed to determine if research implementation behaviours of allied health professionals who work with children with cerebral palsy can be improved via a multi-strategy knowledge translation intervention, and to establish if children's health outcomes can be improved by routine clinical 
assessment. The current paper addresses the supports and barriers to implementation of routine clinical assessment at the commencement of the knowledge translation intervention study.

\section{Ethical Approval}

Ethical approval for the 'Cerebral Palsy Check Up: Providing the best service at the best time' study was granted by the Human Research Ethics Committee of Australian Catholic University (Reference: 2012 309V), the Victorian Department of Education and Early Childhood Development (Reference: 2013_001962) and the Cerebral Palsy Alliance Research Ethics Committee (Reference: 2013-04-02). Approval documents from the Australian Catholic University Research Ethics Committee were lodged and accepted by each partner organisation's ethics committee or Chief Executive Officer.

\section{Participants and recruitment}

Participants were occupational therapists, physiotherapists and speech pathologists (allied health professional, AHPs) employed by five Australian disability service organisations providing services to children with cerebral palsy and their families across four states (Victoria, New South Wales, Tasmania, South Australia). Each organisation's involvement in the project was endorsed by its Chief Executive Officer. All participants provided written informed consent.

Routine clinical assessment procedures, supported by the provision of an electronic cerebral palsy clinical outcomes database, were introduced in June 2013 at four of the five participating organisations ('commencing KT' group). Procedures were already in place at the fifth organisation, ('comparison' group), and had been part of mandated service delivery for a sub-group of clients attending that organisation since 2011. Professional development days were convened at the 'commencing $\mathrm{KT}^{\prime}$ ' organisations to provide standardised training on clinical measurements required as part of the routine clinical assessment procedure that was being introduced. 


\section{Data Collection}

(1) Questionnaires: Participants in the commencing KT group completed the Supports and Barriers Questionnaire ${ }^{12}$ (adapted with permission) during a one hour data collection session held at the organisation. Provision was made for participants to complete the questionnaire independently if they were unable to attend the session. Participants in the 'comparison' group completed the questionnaire at team meetings within their organisation. Participants described or listed perceived supports, barriers and strategies to implementation of routine clinical assessment, addressing each of five domains: organisational structure, organisational resources, therapists employed at the organisation, measures included in the routine assessment, and children and families attending the organisation. Participants also rated the extent to which they considered each of these domains to be a support or barrier to implementation of routine clinical assessment using an 11-point Likert scale $(-5$, barrier, to +5 , support).

Demographic data relating to participants' professional discipline, number of years practicing, number of years working in the disability field and formal postgraduate education were collected.

(2) Focus groups: All participants were invited by email to focus groups convened during work hours at their employing organisation. Four independent, experienced facilitators (one based in each Australian state at which data collection occurred) convened the focus groups. Facilitators were individually briefed on the aims of the study and were provided with a topic guide, the content of which aligned with the domains of the Supports and Barriers Questionnaire. They were supported during the focus group by a research assistant who acted as scribe.

In the focus group participants were asked to discuss perceived supports and barriers to implementation of routine clinical assessment. They were asked to consider the impact of organisation structure and resources currently available. The groups took place within two months of completion of the Supports and Barriers Questionnaire, were typically one hour in duration, and 
were audio-recorded and subsequently transcribed. Facilitator and scribe field notes were collated and used to triangulate the data. Data saturation was not formally evaluated as the perceptions of AHPs in all participating organisations were desired and findings integrated during analyses with the qualitative data obtained using the Supports and Barriers Questionnaire.

3. Organisational profiles: Each participating service completed a short questionnaire detailing organisational characteristics, including the size and number of sites, staff numbers and roles, funding sources, and numbers and profile of children receiving services (multiple diagnoses or only cerebral palsy).

\section{Data Analysis}

Quantitative data from the Supports and Barriers Questionnaire were managed using SPSS version 20. These data were summarised using descriptive statistics and differences between the comparison and commencing KT groups evaluated using the Mann Whitney U-test.

Qualitative data were managed using NVivo 10. Data from the Supports and Barriers Questionnaire were analysed inductively using thematic analysis ${ }^{13}$; data from the focus groups were analysed deductively (see figure 1).

All data reporting perceived supports, barriers and strategies in each of the five domains of the Supports and Barriers Questionnaire were coded by one researcher (CK) using an inductive approach. Inductive coding ensured that all data were analysed and emergent themes identified, not just those domains that were components of the Supports and Barriers Questionnaire. Data pertaining to fifteen randomly selected codes (five for each of supports, barriers and strategies) in each domain were independently reviewed by a second researcher (CI, LQ or NS) to ensure interpretative consistency. Statements describing the meaning of the randomly selected codes were developed independently by pairs of assessors, compared and discussed by the whole authorship team. Next, evaluation of similarities and differences in codes associated with supports, barriers and 
strategies across domains permitted derivation of categories. These categories were discussed and agreed by the team.

Figure 1: Diagram of qualitative data analysis process

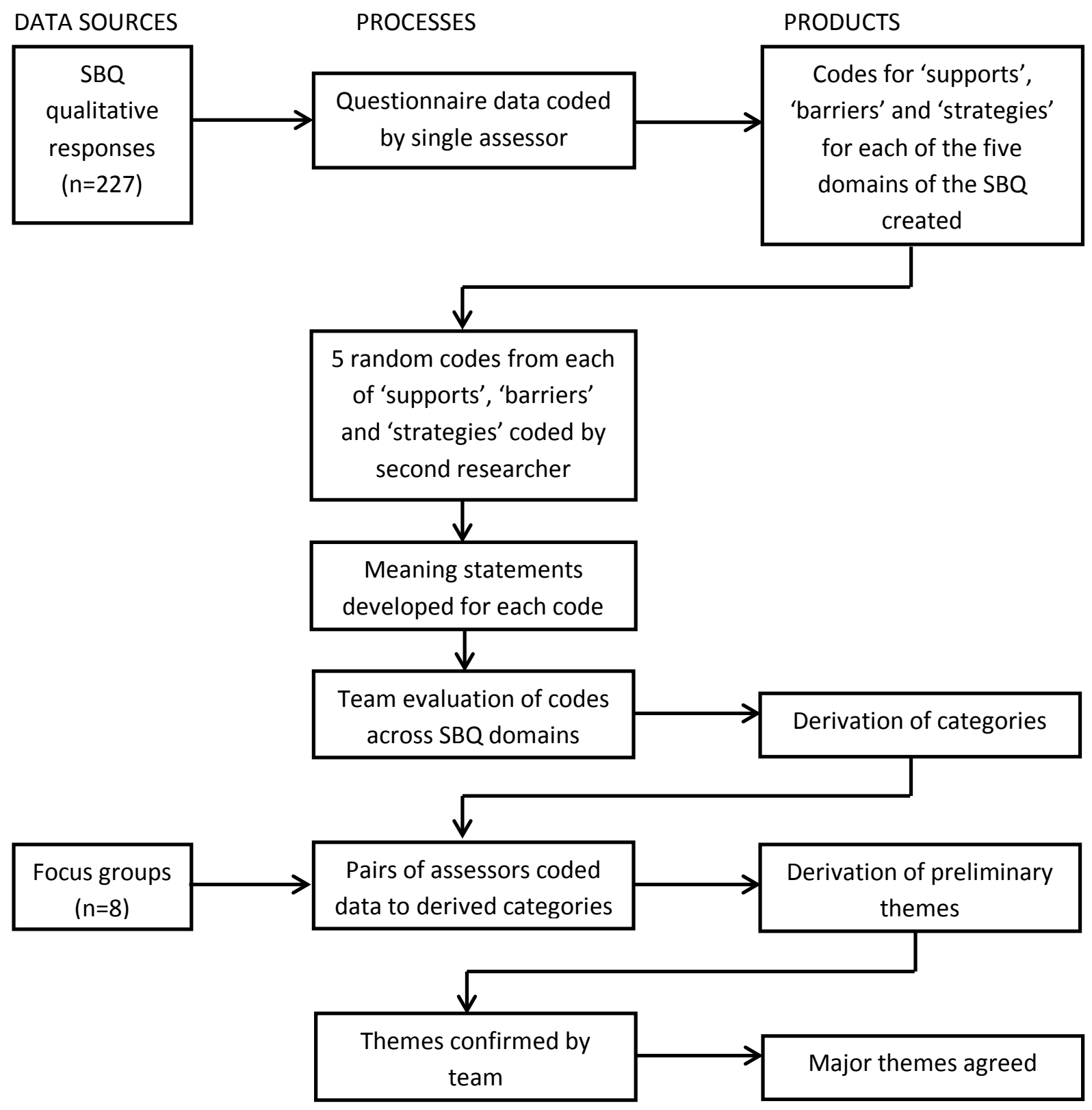


Focus groups data were independently coded by pairs of assessors using the categories derived from the questionnaire data as a framework. Comparison of coding between assessors ensured interpretative consistency. Analysing the focus group data in this way permitted iterative discussion of data that arose during focus groups that was potentially divergent to the questionnaire and ensured that all data were described comprehensively. Data relating to each derived category were compiled, grouped into preliminary themes and reviewed by the team. Final consensus on themes was achieved through discussion.

The results are presented using a side-by-side approach as follows: i) an overview of the characteristics of the included organisations and participants; ii) perceptions of supports and barriers to routine clinical assessment, quantitative data; iii) perceptions of supports and barriers to routine clinical assessment, qualitative data; iv) comparison of quantitative and qualitative results; v)an appraisal of the differences between the supports and barriers perceived in the commencing KT organisations and the comparison organisation; and vi) an overarching synthesis of findings.

\section{Results}

\section{(i) Characteristics of organisations and participants}

The five organisations ranged in size from a small provider with less than four equivalent full-time allied health positions and serving less than 60 clients with neurodevelopmental disabilities, to large state-wide organisations serving diagnostically diverse client groups and providing a range of clinical and support services (table 1).

Two hundred and twenty seven participants completed the Supports and Barriers Questionnaire at baseline (table 2). Eight focus groups including 37 participants were completed. 
Table 1: Characteristics of participating organisations

\begin{tabular}{|c|c|c|c|c|c|}
\hline \multirow[b]{2}{*}{ organisation } & \multirow{2}{*}{$\begin{array}{l}\text { Comparison } \\
1 \\
\end{array}$} & \multicolumn{4}{|c|}{ Commencing KT } \\
\hline & & 2 & 3 & 4 & 5 \\
\hline $\begin{array}{l}\text { No. of sites therapy services } \\
\text { delivered from }\end{array}$ & 16 & 1 & $\begin{array}{l}4 \text { (plus } \\
\text { regional } \\
\text { service) }\end{array}$ & $\begin{array}{l}2 \text { (plus } \\
\text { outreach } \\
\text { clinics) }\end{array}$ & 8 \\
\hline \multicolumn{6}{|l|}{ Funding source (\%) } \\
\hline State & 60 & 10 & 63 & 85 & 76 \\
\hline Philanthropic & 30 & 90 & 10 & 15 & - \\
\hline Other & 10 & - & 27 & - & 24 \\
\hline Total staff $(n=,[E F T])$ & $233[184.4]$ & $12[5.3]$ & $152[91.7]$ & 85 [68.4] & $127[75.0]$ \\
\hline Physiotherapists & $38[28.8]$ & $5[2.0]$ & 31 [17.3] & 15 [12.5] & 16 [11.1] \\
\hline Occupational therapists & 62 [49.9] & $2[0.8]$ & 34 [18.1] & $22[15.8]$ & $22[13.1]$ \\
\hline Speech pathologists & $42[35.9]$ & $2[0.7]$ & $23[13.1]$ & $15[14.4]$ & $26[13.0]$ \\
\hline Other staff (prof\&admin) & $84[59.8]$ & $2[1.0]$ & $58[38.2]$ & 33 [23.7] & NS \\
\hline Senior executives & $10[10]$ & $1[0.8]$ & $6[6]$ & $3[3]$ & NS \\
\hline \multicolumn{6}{|l|}{ Client profile } \\
\hline Diagnoses & CP \& other & CP \& other & CP \& other & CP \& other & CP \& other \\
\hline Age groups & $\begin{array}{l}\text { El, Sch, } \\
\text { Adult }\end{array}$ & $\mathrm{El}, \mathrm{Sch}$ & El, Sch & $\begin{array}{l}\text { El, Sch, } \\
\text { Adult }\end{array}$ & $\mathrm{El}, \mathrm{Sch}$ \\
\hline Total no. of clients & $1275^{*}$ & 58 & 1157 & $4576^{\wedge}$ & 630 \\
\hline Clients with CP aged 3-6y & 92 & 25 & 130 & & 20 \\
\hline Clients with $\mathrm{CP}$ aged $7-18 \mathrm{y}$ & 242 & 26 & 399 & $160(3-18 y)$ & 85 \\
\hline $\begin{array}{l}\text { No. of focus groups } \\
\text { conducted ( } n=\text { participants in } \\
\text { each group) }\end{array}$ & $\begin{array}{l}2(n=4 \text { and } \\
n=4)\end{array}$ & $1(n=5)$ & $1(n=5)$ & $\begin{array}{l}2(n=6 \text { and } \\
n=4)\end{array}$ & $\begin{array}{l}2(n=5 \text { and } \\
n=4)\end{array}$ \\
\hline
\end{tabular}

Legend: No., number; EFT, equivalent full time; prof\&admin, professional and administrative; NS, not specified; CP, cerebral palsy; El, early intervention/pre-school; Sch, school-aged (7-18y); Adult $(>18 \mathrm{y})$, years; ${ }^{*}$ clients with contact in previous 6 months, any age and diagnosis; ${ }^{\wedge}$ clients registered in the service 
Table 2: Participant characteristics

\begin{tabular}{|c|c|c|c|}
\hline Characteristic & $\begin{array}{l}\text { Comparison } \\
(n=78) \\
n,(\%)\end{array}$ & $\begin{array}{l}\text { Commencing KT } \\
(\mathrm{n}=149) \\
\mathrm{n},(\%)\end{array}$ & $\begin{array}{l}\text { All participants } \\
(n=227) \\
n,(\%)\end{array}$ \\
\hline \multicolumn{4}{|l|}{ Profession } \\
\hline Occupational Therapy & $36(46.2)$ & $56(37.6)$ & $92(40.5)$ \\
\hline Physiotherapy & $18(23.1)$ & $52(34.9)$ & $70(30.8)$ \\
\hline Speech Pathology & $22(28.2)$ & $38(25.5)$ & $60(26.4)$ \\
\hline Unknown & $2(2.6)$ & $3(2.0)$ & $5(2.2)$ \\
\hline \multicolumn{4}{|l|}{$\begin{array}{l}\text { Highest level of education (in addition } \\
\text { to professional practice degree) }\end{array}$} \\
\hline No additional qualifications & $60(76.9)$ & $106(71.1)$ & $166(73.1)$ \\
\hline Post-graduate certificate & $3(3.8)$ & $16(10.7)$ & $19(8.4)$ \\
\hline Post-graduate diploma & $4(5.1)$ & $6(4.0)$ & $10(4.4)$ \\
\hline Masters (by coursework) & $8(10.3)$ & $15(10.1)$ & $23(10.1)$ \\
\hline Masters (by research) & $0(0)$ & $1(0.7)$ & $1(0.4)$ \\
\hline $\begin{array}{l}\text { Doctoral degree (PhD or clinical } \\
\text { doctorate) }\end{array}$ & $1(1.3)$ & $2(1.3)$ & $3(1.3)$ \\
\hline Unknown & $2(2.6)$ & $3(2.0)$ & $5(2.2)$ \\
\hline English as first language & $73(93.4)$ & $139(93.3)$ & $212(93.4)$ \\
\hline \multicolumn{4}{|l|}{$\begin{array}{l}\text { Self-nomination of expertise in } \\
\text { paediatric rehabilitation }{ }^{\text {a }}\end{array}$} \\
\hline Novice & $15(19.2)$ & $32(21.5)$ & $47(20.7)$ \\
\hline Intermediate & $43(55.1)$ & $85(57.0)$ & $128(56.4)$ \\
\hline Expert & $17(21.8)$ & $29(19.5)$ & $46(20.3)$ \\
\hline \multirow[t]{2}{*}{ Unknown/missing data } & $3(3.8)$ & $3(2.0)$ & $6(2.6)$ \\
\hline & & & mean (SD) \\
\hline Years since graduation & $11.0(11.3)$ & $12.5(10.3)$ & $11.9(10.6)$ \\
\hline Years clinical experience in disability & $9.5(9.7)$ & $10.4(9.0)$ & $10.1(9.2)$ \\
\hline
\end{tabular}

n, number; SD, standard deviation; ${ }^{\text {a }}$ ated according to the definitions provided by King et al[15].

\section{(ii) Perceptions of supports and barriers to routine clinical assessment, quantitative data}

Participants rated all five domains of the Supports and Barriers Questionnaire positively, indicating

that overall they perceived their organisational structure, organisational resources, therapists

employed at the organisation, measures included in routine assessment, and children and families attending the organisation to be supports to implementation of routine clinical assessment. 
Organisational resources' was the lowest rated domain, and was the domain rated as a barrier by the greatest proportion of respondents (see figure 2 and table 3 ).

Figure 2. Boxplot demonstrating median scores, interquartile range, and range for each domain of the $S B Q$ as rated by AHPs in the comparison group and the commencing KT group

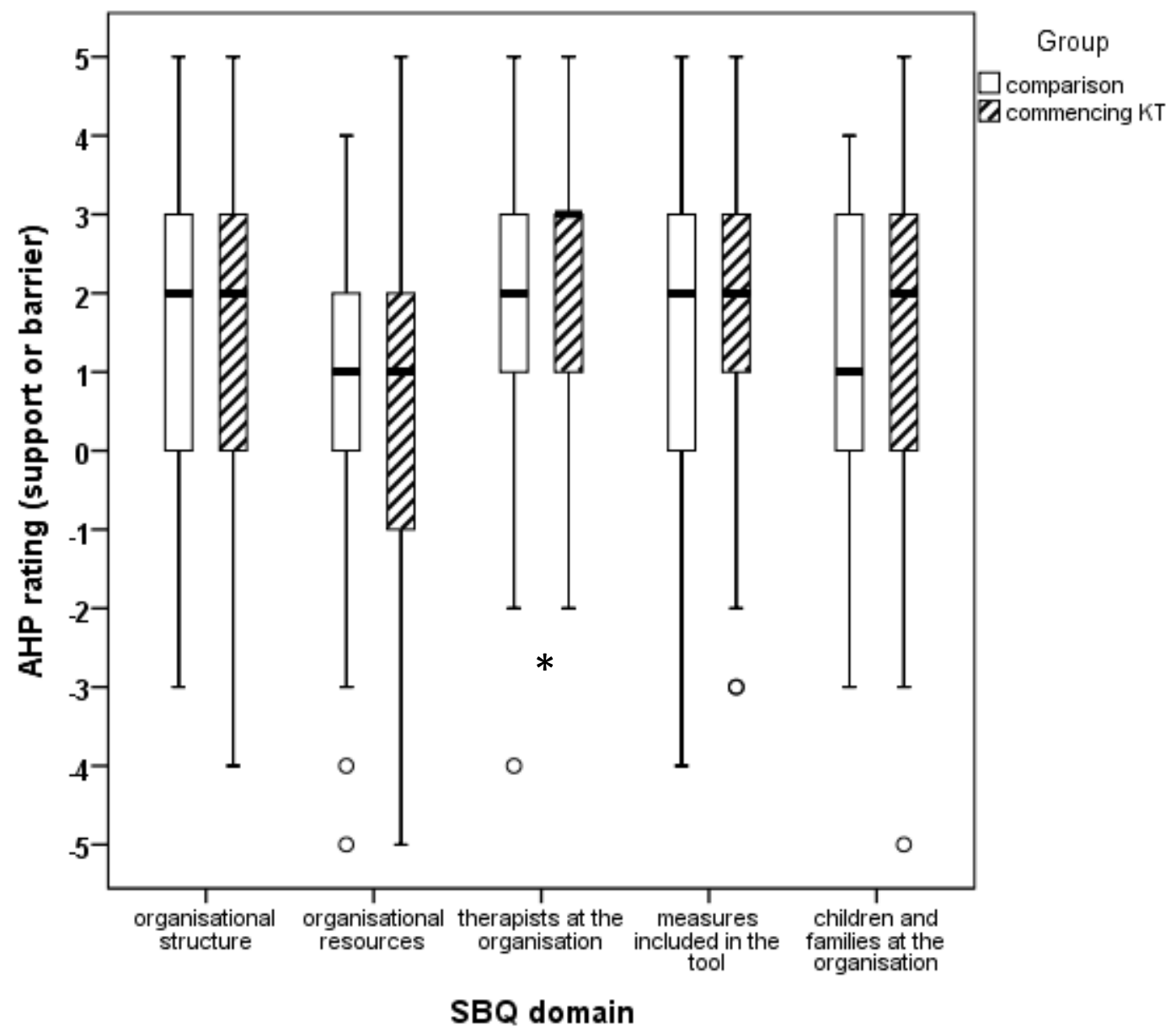

Legend: ${ }^{*} p<0.05$ (Mann-Whitney $U$ test: $U=4236.0 ; \mathrm{n}_{1}=73, \mathrm{n}_{2}=140 ; p=0.037[2$ tailed]) 
Table 3. Mean ratings of SBQ domains and percentage of therapists rating each domain as a barrier

\begin{tabular}{|c|c|c|c|c|c|c|}
\hline \multirow[b]{2}{*}{ SBQ domain } & \multicolumn{3}{|c|}{ Comparison group } & \multicolumn{3}{|c|}{ Commencing KT group } \\
\hline & $n=$ & $\begin{array}{l}\text { Mean } \\
\text { rating } \\
{[95 \% \mathrm{Cl}]}\end{array}$ & $\begin{array}{c}\% \text { of } \\
\text { respondents } \\
\text { rating this } \\
\text { domain as a } \\
\text { barrier }\end{array}$ & $n=$ & $\begin{array}{l}\text { Mean } \\
\text { rating } \\
{[95 \% \mathrm{Cl}]}\end{array}$ & $\begin{array}{c}\% \text { of } \\
\text { respondents } \\
\text { rating this } \\
\text { domain as a } \\
\text { barrier }\end{array}$ \\
\hline $\begin{array}{l}\text { organisational } \\
\text { structure }\end{array}$ & 77 & $\begin{array}{c}1.44 \\
{[1.03-1.85]}\end{array}$ & 16.9 & 144 & $\begin{array}{c}1.27 \\
{[0.90-1.64]}\end{array}$ & 20.8 \\
\hline $\begin{array}{l}\text { organisational } \\
\text { resources }\end{array}$ & 78 & $\begin{array}{c}0.99 \\
{[0.54-1.44]}\end{array}$ & 23.1 & 146 & $\begin{array}{c}0.60 \\
{[0.22-0.97]}\end{array}$ & 32.9 \\
\hline $\begin{array}{l}\text { therapists } \\
\text { employed at } \\
\text { the } \\
\text { organisation }\end{array}$ & 73 & $\begin{array}{c}1.78 \\
{[1.38-2.18]}\end{array}$ & 8.2 & 140 & $\begin{array}{c}2.25 \\
{[1.97-2.53]}\end{array}$ & 8.6 \\
\hline $\begin{array}{l}\text { measures } \\
\text { included in the } \\
\text { routine } \\
\text { assessment } \\
\text { tool }\end{array}$ & 74 & $\begin{array}{c}1.53 \\
{[1.09-1.97]}\end{array}$ & 12.2 & 141 & $\begin{array}{c}1.92 \\
{[1.64-2.21]}\end{array}$ & 9.2 \\
\hline $\begin{array}{l}\text { children and } \\
\text { families } \\
\text { attending the } \\
\text { organisation }\end{array}$ & 69 & $\begin{array}{c}1.30 \\
{[0.92-1.69]}\end{array}$ & 11.6 & 142 & $\begin{array}{c}1.61 \\
{[1.31-1.91]}\end{array}$ & 12.0 \\
\hline
\end{tabular}

(iii) Perceptions of supports and barriers to routine clinical assessment, qualitative data

Analyses of qualitative data from the Supports and Barriers Questionnaire identified 15 categories from which five major themes were developed (table 4). Subsequent analyses of focus group data resulted in no further categories or themes. 
Table 4: Overarching themes and categories

\begin{tabular}{|c|c|}
\hline Theme & Categories and descriptions \\
\hline \multirow{3}{*}{$\begin{array}{l}\text { MOTIVATED TO } \\
\text { ADOPT ROUTINE } \\
\text { CLINICAL } \\
\text { ASSESSMENT }\end{array}$} & $\begin{array}{l}\text { Staff and organisation are positive: the organisation and staff are positive } \\
\text { about implementation of routine clinical assessment; positive organisational } \\
\text { mandate. }\end{array}$ \\
\hline & $\begin{array}{l}\text { Routine clinical assessment adds value: perception that participation in the } \\
\text { research project 'adds value' for the organisation, AHPs and families via } \\
\text { provision of robust assessment, training and tools, clear reporting and } \\
\text { enhanced communication. }\end{array}$ \\
\hline & $\begin{array}{l}\text { How the team works together: management support, peer support and } \\
\text { consistency of message evident at different levels in the organisation. }\end{array}$ \\
\hline \multirow{3}{*}{$\begin{array}{l}\text { ACQUIRING AND } \\
\text { UTILISING } \\
\text { EXPERTISE }\end{array}$} & $\begin{array}{l}\text { Training, supervision, support: availability of formal and informal ongoing } \\
\text { training opportunities; supervision and mentoring; knowledge broker, clinical } \\
\text { advisor and peer support; acquisition and dissemination of expertise. }\end{array}$ \\
\hline & $\begin{array}{l}\text { Alignment with practice: elements of the routine clinical assessment are } \\
\text { already current practice in the organisation. }\end{array}$ \\
\hline & $\begin{array}{l}\text { Expertise exists: adequate expertise is already present in the organisation, } \\
\text { typically provided by knowledge brokers, clinical advisors or senior clinicians } \\
\text { with experience of working with children with cerebral palsy. }\end{array}$ \\
\hline \multirow{3}{*}{$\begin{array}{l}\text { ENSURING } \\
\text { EFFECTIVE } \\
\text { ONGOING } \\
\text { COMMUNICATION }\end{array}$} & $\begin{array}{l}\text { Clarity of processes / streamlining: policies, procedures and processes are } \\
\text { clear, streamlined and support clinical activities. }\end{array}$ \\
\hline & $\begin{array}{l}\text { Effective ongoing communication: exists between all stakeholders (families, } \\
\text { management and others, including schools and NDIS) }\end{array}$ \\
\hline & $\begin{array}{l}\text { Engaging families: acknowledging that some families are hard-to-reach or } \\
\text { choose not to engage with AHPs or their child's therapy provision; family } \\
\text { choice not to engage with project; relationships between organisations and } \\
\text { families. }\end{array}$ \\
\hline \multirow{4}{*}{$\begin{array}{l}\text { AVAILABILITY AND } \\
\text { DISTRIBUTION OF } \\
\text { RESOURCES }\end{array}$} & $\begin{array}{l}\text { Resources: Availability of non-AHP resources; technology and infrastructure; } \\
\text { administrative support; clinical tools. }\end{array}$ \\
\hline & $\begin{array}{l}\text { Workload considerations: how the organisation manage AHP staffing; full- } \\
\text { time and part-time staff; caseloads; skill mix; quarantined time for assessment } \\
\text { and/or training. }\end{array}$ \\
\hline & $\begin{array}{l}\text { Financial implications of surveillance: cost to the organisation, or the family in } \\
\text { providing or receiving routine clinical assessment; impact of the NDIS on } \\
\text { routine clinical assessment and associated training time for therapists }\end{array}$ \\
\hline & $\begin{array}{l}\text { Organisational structure and delivery of clinical services: size and scope of } \\
\text { organisation; geographical spread; range of services provided; range of client } \\
\text { groups supported }\end{array}$ \\
\hline \multirow{2}{*}{$\begin{array}{l}\text { THERAPIST } \\
\text { PERCEPTIONS OF } \\
\text { CHILD AND } \\
\text { FAMILIES' WISHES }\end{array}$} & $\begin{array}{l}\text { Therapist perceptions of child and family views of assessment: including the } \\
\text { actual assessment process, time, utility, relevance, the child's ability to } \\
\text { tolerate or co-operate with the procedures }\end{array}$ \\
\hline & $\begin{array}{l}\text { Therapists perceive that families want what's best for their child: Perception } \\
\text { that families' desire the best possible care for their child }\end{array}$ \\
\hline
\end{tabular}

NDIS: National Disability Insurance Scheme 


\section{Theme 1: Motivated to adopt routine clinical assessment}

A positive and supportive attitude in the workplace from AHP and management towards implementation of routine clinical assessment, and the larger project, in which this KT strand was embedded, was described.

"I guess when I learnt that the surveillance tools have been used before, the change it's made, the difference it's made for the population in other countries, I'm just like, 'Well we should do this then..!'” (Sub-theme: Routine clinical assessment adds value, Organisation 2)

Participants highlighted the juxtaposition between organisational commitments to routine clinical assessment, manifested by the organisations being research partners in the larger project, with individual AHPs providing voluntary consent to participate. Choosing to participate in the larger project therefore became a proxy for choosing to engage in routine clinical assessment. The impact on clinical teams of individual AHPs deciding not to participate in the larger project was also considered: this spoke to how the team worked together and distribution of workload:

"It [participation in the project] was mostly a mandate.... what we understood was, on an individual basis it was optional, at an organisational basis we had decided that we would go ahead. Any person choosing not to participate, I guess, you would then feel that perhaps the other people participating have an extra burden on them in terms of time, so it's a little bit about, you know, sharing the load being a part of a project, so in that regards, you know, usually it's not feeling that optional." (Sub-theme: Staff and organisation are positive, Organisation 4)

"Then we've got therapists that may have not signed up to the project and that's tricky, or staff that are here that aren't keen." (Sub-theme: Staff and organisation are positive, Organisation 5) 


\section{Theme 2: Acquiring and utilising expertise}

Participants acknowledged the expertise within participating organisations, teams and peer groups. They reported valuing expertise acquired through formal and informal strategies and learning approaches. Formal clinical supervision, scheduled professional development days and funding for external training were typically available:

"I think we're well supported around supervision and really encouraged to have monthly supervision or even more often .... ." (Sub-theme: training, supervision, support, Organisation 1)

"The support to actually do professional development is really strong and it's a strong part of the culture." (Sub-theme: training, supervision, support, Organisation 2)

However participants reported the availability of, and access to, specific training or external expert clinicians was not universal. They acknowledged the implications of this on accuracy of clinical measurements and their lack of exposure to what they perceived to be best practice.

"... the assessments, you know, you're meant to go off and be credentialed to implement them .... to ensure reliability and if we're not trained in that, then what we're measuring may not actually be reliable." (Organisation 4)

"Another barrier is access to specialists, so a lot of the specialist clinics and services aren't run in [our region]." (Sub-theme: [lack of] expertise exists, Organisation 4)

\section{Theme 3: Ensuring effective ongoing communication}

Participants expressed the need for clear, sustained communication at all organisational levels and between stakeholders. They described how procedures for implementing routine clinical 
assessment varied between and within organisations. A desire for clarity around processes was specifically and consistently articulated:

"having a policy, a flow chart or something like that ... would be helpful." (Sub-theme: [lack of] clarity of processes, Organisation 1)

Participants discussed confusion over processes which they contextualised against a background of constant change. For example in one organisation, participants reported that processes, paperwork, methods of assessment and treatment planning had changed over a very short period of time. Indeed, some participants reported the rates of change and email communications about change were overwhelming, and ultimately ineffective:

"a lot of information comes through on our emails, ... when I see emails from addresses that I'm not $100 \%$ familiar with...I'm just kind of like, oh okay great, delete. ..... So for me email isn't the best way of communication. " (Sub-theme: Effective ongoing communication, Organisation 5)

Tailoring information to different stakeholders and delivering it at the right time was identified by participants as a potential issue, particularly in the context of engaging families. Participants thought families would respond more readily to a familiar clinician. Specific difficulties were reported by participants when trying to engage with families from non-English speaking backgrounds (lack of appropriate written materials and increased appointment time required for interpreters); families whose children received therapy services in a special school setting and who travelled by bus (where family members were not often present for therapy); families that had simply 'drifted away' from clinical services; and families that were perceived to be juggling multiple appointments and priorities for their child. 


\section{Theme 4: Availability and distribution of resources}

A need for increased resourcing was reported at all focus groups. Physical resources (i.e. clinical space, assessment kits/outcome measures, computer access) were reported to be adequate by the majority of participants. The exception was participants working in organisations with a larger geographical spread, or that operated from multiple sites, who reported not necessarily having access to all tools at all sites. Lack of administrative support was identified as a barrier and was inextricably linked with workload, such as time spent entering data from routine clinical assessments or arranging appointments. Some participants reported that their diaries were booked months in advance and co-ordinating time with other staff to complete joint assessments was difficult. Although one organisation had provided 'additional time' to complete routine clinical assessment, a prevailing sense of 'not enough time' was apparent across all organisations and resulted in participants feeling pressured:

"this is ... on top of what we're doing and we're already really, really stretched for time." (Sub-theme: workload considerations, Organisation 3)

High staff turnover, lengthy waiting lists and diversity in organisations' client bases were cited as barriers to implementation of routine clinical assessment for children with cerebral palsy:

"staff turnover is probably something that in [our organisation] is a significant issue, because every time you have staff turnover you need to re-train staff which is a significant cost. ...most of us work with a mixed caseload so CP is a small part of our focus." (Sub-theme: workload considerations, Organisation 4) "with more clients coming, - and we haven't actually had staff increase yet to match that.." (Sub-theme: workload considerations, Organisation 3) 
Although focus groups participants were all engaged in direct delivery of clinical services, they discussed how funding and contractual factors impacted on routine clinical assessment. Participants expressed uncertainty about sustaining routine clinical assessment in the context of a new national funding model for disability services (National Disability Insurance Scheme, NDIS; commenced July 2013) and queried if families would allocate funding to 'assessment' as opposed to 'intervention'. Contractual arrangements with the special education sector were not perceived to be supportive of routine clinical assessment by participants.

Geographical spread of the organisation was considered an influencing factor: participants employed by organisations covering larger geographical areas, or having multiple sites acknowledged wide socioeconomic client diversity, long distances from the clinical base to client homes, and in two instances, differing AHP practices between sites within the same organisation, as barriers to implementation of routine clinical assessment.

Theme 5: Therapist perceptions of child and families' wishes

Participants perceived some children may not tolerate the full clinical assessment (e.g. fatigue, co-operation with measurement procedures, duration of assessment), particularly younger children and children with greater gross motor limitations. Other participants felt parents would prioritise 'intervention' over 'assessment', particularly if the proposed assessment was not aligned with the family's goals:

"A lot of families want intervention. Sometimes it can be seen that we're constantly assessing and the families are kind of like, well, we know our child has been assessed and assessed and they want the intervention..." (Sub-theme: Therapist perceptions of child and family views of assessment, Organisation 4) 
Contrary to this was the opinion of some participants that health literate parents would support routine assessment, and valued regular monitoring of their child:

"I guess it depends on how well the families are educated because if you felt that your child was going to have [routine assessment] that may help prevent a contracture or something like that developing, then the family should be happy for you to take those measures,." (Subtheme: Therapists perceive that families want what's best for their child, Organisation 3)

\section{iv) Comparison of quantitative and qualitative results}

The positive overall ratings noted in the quantitative data were typically substantiated by the qualitative data, with significant alignment between the domains in the Supports and Barriers Questionnaire and the themes derived from the qualitative data. The breadth of opinion expressed within the open-ended questionnaire items and the focus groups was also reflected in the wide range of scores in the quantitative ratings submitted by respondents on the Supports and Barriers Questionnaire. Interestingly, the most positively rated Supports and Barriers Questionnaire domain, 'therapists employed at the organisation' aligns well with the 'motivation to adopt the routine clinical assessment' theme that arose from the qualitative data. This theme speaks to organisational readiness and individual therapist attitudes to the introduction of routine clinical assessment. Similarly, the least positively rated questionnaire domain, 'organisational resources', has clear associations with the qualitative theme 'availability and distribution of resources'.

\section{(v) Differences between the commencing $K T$ group and the comparison organisation.}

There were no differences between the groups in ratings on four of the five domains of the Supports and Barriers Questionnaire (fig 2). The exception was 'therapists at the organisation' which participants in the commencing $\mathrm{KT}$ group rated more positively than respondents in the comparison group $\left(\mathrm{U}=4236.0 ; \mathrm{n}_{1}=73, \mathrm{n}_{2}=140 ; p=0.037[2\right.$ tailed $\left.]\right)$. 
High 'motivation to adopt the routine clinical assessment' was evident across all participating organisations, although two organisations in the commencing KT group felt the increased focus on children with cerebral palsy was to the detriment of children from other diagnostic groups, or children with cerebral palsy who had not consented to participate in the routine assessment:

"we're doing things differently for those kids who have signed up than we [usually] would, so they're getting a different service .... you want to be offering the best service but I feel like I'm going to do these things where I otherwise wouldn't have done those with that child and you do feel like just because they fit into that criteria they get that extra input..." (Subtheme: CP Check Up adds value, Organisation 5)

Participants in the comparison organisation reflected on the value of routine assessment to clinicians and families, questioning whether it was of greatest value for clinical decision-making or served more as a database of medical records, and whether completion of all aspects of the assessment was truly relevant to child and family goals. Participants in the commencing KT group did not appear to reflect on the routine clinical assessment in this way.

Comments from the comparison organisation in relation to 'acquiring and utilising expertise' were very positive, with participants reporting a strong culture of training, supervision and support. Two commencing KT organisations were similarly positive while specific challenges were evident at two of the commencing KT organisations. One organisation indicated less expertise in some components of the routine clinical assessment while the other indicated a lack of training and access to specialists that they attributed to geographical isolation.

'Ensuring effective communication' was perceived by respondents as a significant barrier to implementing routine clinical assessment. Participants in four of the five participating organisations commented on lack of clarity of processes and poor delegation of roles and responsibilities, 
compounded by a perception of constant change, or a fast rate of change. In the fifth organisation, participants attributed the effectiveness of their communication processes to the physical proximity of the team and internal processes to support implementation of the routine clinical assessment. This finding did not appear to be influenced by the length of time routine clinical assessment had been in use.

When considering 'availability and distribution of resources', the advanced stage of implementation of the comparison organisation was evident. Challenges reported at the comparison organisations related to sustainability of routine assessment and focused on staffing (perceived high staff turnover rates, insufficient staff to deal with waiting lists and the need for additional administrative support). Participants in the commencing KT group highlighted more pragmatic implementation barriers such as lack of access to assessment tools, and different service delivery models within the same organisation.

In relation to 'therapists' perceptions of child and families wishes,' participants in the comparison organisation did not report co-operation of the child with assessment procedures to be a barrier, whereas in the commencing KT group this was a commonly perceived barrier to implementation of routine clinical assessment. A perception by participants that families may value 'intervention' over 'assessment' was apparent across all organisations.

\section{(vi) Overarching synthesis of findings}

Implementing routine multi-disciplinary clinical assessment of children with cerebral palsy using a structured evidence-based approach was perceived to occur within an ever-changing organisational landscape. Situated alongside concurrent radical changes to Australian Federal Government provision of funds for services through the National Disability Insurance Scheme (NDIS), the participants described tensions between their motivation to adopt best-practice, and ubiquitous changes to organisational processes that challenged their capacity to ensure high quality communication, and manage equitable and efficient use of resources. The presence of expertise and 
alignment of processes with existing practices supported respondent perceptions of capacity to change. Participants perceived a lack of autonomy associated with existing prescriptive contractual obligations in one organisation and funding models of the new NDIS that changed decision making. This created additional uncertainty and placed a high premium on family education about the relevance and value of routine clinical assessment.

\section{Discussion}

This study describes allied health perceptions of factors influencing the implementation of routine clinical assessment for children with cerebral palsy. Involvement of 227 individual therapists enhances our ability to comprehend the issues at hand and to contextualise the impact of the organisational stage on implementation of routine clinical assessment. The study predominantly utilised qualitative methods however quantitative data is important for summative and comparative purposes in this study, and will also be used for future longitudinal comparisons.

\section{Trustworthiness and transferability}

The wide range of respondents coupled with triangulation of methods, analysts and data sources enhance the credibility of the study. Detailed descriptions of the organisational settings and participants have been provided to support reader interpretation and permit transferability. Dependability was achieved via a clear audit trail of processes applied at the different stages of the study, examination of field notes and by multiple team members checking analyses. Confirmability was achieved via audit of the analysis by multiple team members who all contributed to decisionmaking and by triangulation of the survey responses with the focus group data.

A number of limitations to the study exist. Although a modified convergent parallel mixed methods approach was undertaken, elements of the qualitative analyses could be considered to be explanatory, in that focus group data were deductively analysed using the framework derived from inductive analyses of the qualitative data returned in the Supports and Barriers Questionnaire. Nonetheless, we are confident that no emergent themes were overlooked in the focus group data 
due to our robust method of having pairs of assessors independently code the focus group data and iteratively discuss findings. The nature of our volunteer sample for the focus groups coupled with the potential for group dynamics to influence participation levels were identified as particular threats to the range of opinions expressed, however it was not possible to purposively sample focus group participants as individual AHP characteristics were not collected as part of the Supports and Barriers Questionnaire. This means that it is possible that the focus group participants were not reflective of the wider AHP participant group, but this is refuted in part by the close alignment between the quantitative domain ratings and the qualitative themes that arose. The potential impact of group dynamics was reduced by engagement of skilled, experienced facilitators who were well briefed in advance of the sessions. The lack of formal member checking of the derived themes may have threatened the credibility of the findings, however focus group facilitators summarised key aspects of the discussion at the end of each focus group and asked participants to confirm their accuracy. Feedback on derived themes was also provided to AHPs in the 'commencing KT' group at study training days, and to all organisations via provision of site-specific reports, providing an opportunity for feedback and discussion.

\section{Adopting innovation}

Implementation of the routine clinical assessment process required systemic change in participating organisations. Organisational commitment to change was manifested at senior management level by the organisations' initial 'buy in', suggesting the value of routine clinical assessment for children with cerebral palsy was understood. This was echoed by participants' positive perceptions of the benefits conferred by routine clinical assessment. However, successful implementation was not guaranteed; indeed evidence suggests behaviour change is required at multiple organisational levels, is complex, and may be subject to competing factors, many of which are beyond the control of the practitioner

${ }^{6}$. Over-arching determinants of success are the socio-political context, characteristics of organisations, characteristics of the adopting person (the user) and characteristics of the 
innovation $^{8}$; success can be compromised at any stage of the innovation process: dissemination, adoption, implementation and continuation ${ }^{8}$.

The impact of social-political context on implementation of routine clinical assessment cannot be under-estimated. In addition to implementation of routine clinical assessment, two organisations were undergoing internal restructuring, and a third was negotiating new service agreements. However, perhaps of most significance in this study was the introduction of the NDIS that occurred concurrently with implementation of routine clinical assessment. This change in funding model has re-shaped the landscape in which disability services organisations in Australia operate $^{14}$ and participant awareness of the impact of the NDIS on their organisation's ability to provide routine clinical assessment permeated the data. The uncertainty expressed by participants about the sustainability of routine clinical assessment, in the context of NDIS is credible. The changes to funding also made participants question the extent to which families would value routine assessment in the future, particularly if intervention time was perceived to be 'sacrificed' on behalf of assessment time. These factors, although typically outside health professionals' sphere of influence, doubtlessly influenced perceptions regarding implementation of routine clinical assessment. What is not known is the extent to which health professional perceptions of families' views actually aligns with the views of families.

Characteristics of organisations reported as determinants of innovation success include decision-making processes, organisation size, staff turnover, staff capacity and logistical procedures relating to the innovation ${ }^{8}$. This was borne out in our data, however, 'organisational structure' and 'organisational resources', had the lowest mean ratings in the 'commencing KT' group. The qualitative findings provided some explanation of these ratings: for example, the juxtaposition between strong endorsement from senior management but lack of clarity about day-to-day logistics of implementation (procedures and impact on workloads) appeared to culminate in disaffection in some AHPs: "I don't get excited about it [change] anymore. I think that people become optimistic and I, unfortunately, just kind of go, great, something else that we have to adapt to that's going to 
change... again.(Organisation 5)" Qualitative data suggested that (i) multiple communication strategies are required; (ii) 'less is more' (that is, unnecessary communication should be avoided); (iii) timing is critical: information should be provided at the point of need; and (iv) that relevant communication and information is stored and indexed appropriately for ease of future access.

Known determinants of innovation success relating to the AHP include support from other staff; the knowledge, skills and self-efficacy of the AHP; the extent to which the AHP expects the patient to co-operate and be satisfied with the innovation; the extent to which the AHP perceives ownership of the innovation; and whether the AHP has ethical problems with the innovation ${ }^{8}$. Determinants relating to AHP knowledge and skills were evident in our study in the theme 'acquiring and utilising expertise'. Approximately $20 \%$ of participants rated themselves as 'experts'. King et al demonstrated that expertise in paediatric rehabilitation therapists was not determined by years of professional experience, but by motivation, openness to experience and the breadth and complexity of clinical experience of the therapist ${ }^{15}$.

Participants may have perceived their clinical autonomy to be undermined by the provision of a standard electronic clinical outcomes database and the associated protocol requirements about frequency of re-assessment. Organisational changes to administrative and assessment processes in response to the NDIS may also have compounded perceptions of lack of autonomy. Conversely, these changes may have been viewed as an opportunity to increase the child and families' involvement with assessment, intervention and care-planning, providing a more family-centred approach $^{16}$.

Factors relating specifically to the innovation, that is, routine clinical assessment, are also known to be determinants of its success ${ }^{8}$. Alignment of the new practice with existing practices; perceived 'added value' for clients, staff and the organisation; user-friendliness; and frequency of use are known to affect uptake ${ }^{8}$. Perceived barriers in this study that related directly to the routine clinical assessment tool were similar to those reported by other authors such as lack of time, training or alignment with existing practice ${ }^{17,18}$. Evidence of the advanced implementation stage of the 
comparison organisation with respect to the commencing KT organisations was apparent and could be attributed to mandated use of the tool, positive sustained management endorsement and having good organisational structures in place for training and clinical supervision. Such factors working across multiple levels are known to optimise an organisation's implementation climate ${ }^{19}$.

\section{Implications and Significance}

This study provides an understanding of the challenges perceived by AHPs to implementation of routine clinical assessment procedures and has implications for children with cerebral palsy and their families, AHPs, managers of clinical services, disability services organisations and health and disability policy-makers. The value of routine clinical assessment for children with cerebral palsy is undisputed; however making that a reality for all children with cerebral palsy presents challenges. Perceived barriers to routine clinical assessment varied, highlighting the potential need for tailored KT interventions that address implementation issues specific to the site (and individual therapy teams). Adequate resourcing and sustained, positive, clear communication at multiple levels within organisations were perceived to be critical for success.

Future research will monitor supports and barriers to routine clinical assessment in these organisations over time. Direct feedback from parents and carers of children with cerebral palsy who partake in the routine clinical assessment processes will be sought to establish the acceptability of the procedure and its perceived value to the child, family and other stakeholders.

\section{Acknowledgements}

We acknowledge and thank all of the partner organisations (Cerebral Palsy Alliance, St Giles, Novita Children's Services, Yooralla and Kids Plus) and participating AHPs as well as the children and families who took part, the Steering Committee, including Michael Debinski (Chair) and Sharon Cutrale (consumer representative) and the members of our Local Advisory Committees. 
*The 'Cerebral Palsy Check Up: Providing the best service at the best time' group is:

\section{Chief investigators}

Prof. Christine Imms, Centre for Disability and Development Research, Australian Catholic University Prof. Iona Novak, Cerebral Palsy Alliance; University of Notre Dame

Prof. Dinah Reddihough, Murdoch Childrens Research Institute; University of Melbourne; Royal Children's Hospital, Melbourne

Prof. Nora Shields, La Trobe University; Northern Health

Prof. H. Kerr Graham, Orthopaedic Department, Royal Children's Hospital, Melbourne

Dr. Steven Bowe, Deakin University

\section{Associate/partner investigators}

Ms. Kerry Evans and Dr. Angela Crettenden, Novita Children's Services

Ms. Sarah Foley, Kids Plus Foundation

Dr. Elspeth Froude, Australian Catholic University; St Giles

Dr. Adrienne Harvey, Royal Children's Hospital, Melbourne

Dr. Petra Karlsson and Ms Hayley Smithers-Sheedy, Cerebral Palsy Alliance

Ms. Marisa McCague, Ms. Meredith Fordyce and Mr. Ashley Creighton, Yooralla

Dr. Lyndsay Quarmby, St Giles

Dr. Melinda Randall, Australian Catholic University; Murdoch Childrens Research Institute

\section{Project manager and research assistants}

Dr. Claire Kerr, Centre for Disability and Development Research, Australian Catholic University

Richard Barclay, Cerebral Palsy Alliance; University of Sydney

Mahek Dudhwala, Australian Catholic University

Kanchana Pathirana, Elsa Reuter, Dr. Annemarie Wright, Novita Children's Services

Madeline Rowell, St Giles 


\section{Declaration of Interest}

This partnership project was funded by the Australian National Health and Medical Research Council (APP1055278) and received financial and substantial in-kind support from each partner organisation: Cerebral Palsy Alliance, St Giles, Novita Children's Services, Yooralla and Kids Plus. 


\section{REFERENCES}

1. Hagglund G, Alriksson-Schmidt A, Lauge-Pedersen H, Rodby-Bousquet E, Wagner P, Westbom L. Prevention of dislocation of the hip in children with cerebral palsy: 20-year results of a population-based prevention programme. Bone Joint J 2014;96-b(11):1546-52.

2. Hagglund G, Andersson S, Duppe H, Lauge-Pedersen H, Nordmark E, Westbom L. Prevention of severe contractures might replace multilevel surgery in cerebral palsy: results of a population-based health care programme and new techniques to reduce spasticity. J. Pediatr. Orthop. B 2005;14(4):269-73.

3. Rosenbaum P, Paneth N, Leviton A, Goldstein M, Bax M. The definition and classification of cerebral palsy. Dev. Med. Child Neurol. 2007;49:1-44.

4. Andersson C, Mattsson E. Adults with cerebral palsy: A survey describing problems, needs, and resources, with special emphasis on locomotion. Dev. Med. Child Neurol. 2001;43(2):7682.

5. Research CloH. 2016 28/01/2016. Knowledge translation: definition. <http://www.cihrirsc.gc.ca/e/29529.html >. Accessed 2016 28/01/2016.

6. Scott SD, Albrecht L, O'Leary K, Ball GDC, Hartling L, Hofmeyer A, Jones CA, Klassen TP, Burns KK, Newton AS and others. Systematic review of knowledge translation strategies in the allied health professions. Implement Sci 2012;7(1).

7. Novak I RD, Ketelaar M. Can translation of research information improve outcomes? In: Ronen GM, Rosenbaum PL, editors. Life Quality Outcomes in Children and Young People with Neurological and Developmental Conditions Concepts, Evidence and Practice, Clinics in Developmental Medicine London: Mac Keith Press; 2013. p 265-281.

8. Fleuren M, Wiefferink K, Paulussen T. Determinants of innovation within health care organizations. Literature review and Delphi study. Int. J. Qual. Health Care 2004;16(2):107123. 
9. Grimshaw JM, Eccles MP, Lavis JN, Hill SJ, Squires JE. Knowledge translation of research findings. Implement Sci 2012;7(1).

10. Creswell JW. Research design: Qualitative, quantitative and mixed methods approaches. 2nd ed. Thousand Oaks, CA Sage Publications Inc; 2003.

11. Imms C, Novak I, Kerr C, Shields N, Randall M, Harvey A, Graham HK, Reddihough D. Improving allied health professionals' research implementation behaviours for children with cerebral palsy: protocol for a before-after study. Implement Sci 2015;10(1):16.

12. Rivard LM, Russell DJ, Roxborough L, Ketelaar M, Bartlett DJ, Rosenbaum P. Promoting the use of measurement tools in practice: a mixed-methods study of the activities and experiences of physical therapist knowledge brokers. Phys. Ther. 2010;90(11):1580-90.

13. Braun V, Clarke V. Using thematic analysis in psychology. Qual. Res. Psychol. 2006;3(2):pp.

14. Reddihough DS, Meehan E, Stott NS, Delacy MJ. The National Disability Insurance Scheme: A time for real change in Australia. Dev. Med. Child Neurol. 2016;58:66-70.

15. King G, Currie M, Bartlett DJ, Strachan D, Tucker MA, Willoughby C. The development of expertise in paediatric rehabilitation therapists: The roles of motivation, openness to experience, and types of caseload experience. Aust. Occup. Ther. J. 2008;55(2):108-122.

16. Rosenbaum P, King S, Law M, King G, Evans J. Family-centred service: A conceptual framework and research review. Phys. Occup. Ther. Pediatr. 1998;18(1):1-20.

17. Hanna SE, Russell DJ, Bartlett DJ, Kertoy M, Rosenbaum PL, Wynn K. Measurement practices in pediatric rehabilitation: A survey of physical therapists, occupational therapists, and speech-language pathologists in Ontario. Phys. Occup. Ther. Pediatr. 2007;27(2):25-42.

18. Ketelaar M, Russell DJ, Gorter JW. The challenge of moving evidence-based measures into clinical practice: Lessons in knowledge translation. Phys. Occup. Ther. Pediatr. 2008;28(2):191-206. 
19. Aarons GA, Ehrhart MG, Farahnak LR, Sklar M. Aligning leadership across systems and organizations to develop a strategic climate for evidence-based practice implementation. Annu. Rev. Public Health. Volume 352014. p 255-274. 